\title{
Selective Laser Sintering of Poly(L-Lactide)/Carbonated Hydroxyapatite Nanocomposite Porous Scaffolds for Bone Tissue Engineering
}

\author{
Wen You Zhou', Min Wang'2, Wai Lam Cheung2,* and Wing Yuk Ip ${ }^{3}$ \\ ${ }^{1}$ Biomedical and Tissue Engineering Research Group, Faculty of Dentistry, \\ The University of Hong Kong, 34 Hospital Road, Hong Kong, China \\ ${ }^{2}$ Department of Mechanical Engineering, The University of Hong Kong, \\ Pokfulam Road, Hong Kong, China \\ ${ }^{3}$ Department of Orthopaedics and Traumatology, The University of Hong Kong, \\ Sassoon Road, Hong Kong, China
}

\section{Introduction}

Bone replacements are frequently required to fix damaged tissue due to trauma, tumor resection, and more generally in many surgeries (Navarro et al. 2004). This requirement for new bone is a major clinical and socioeconomic need. There is a driving need in tissue engineering (TE) field to develop scaffolds that guide bone regeneration across defects that are too large to heal naturally. This may be achieved by a multidisciplinary field: bone tissue engineering (BTE) which seeks to apply the scientific principles to engineering of viable substitutes that restore and maintain the function of human bone tissue. There are three key elements for regenerating bone tissues, namely, osteogenic progenitor cells, osteoinductive growth factors and osteoconductive scaffolds (Schieker et al. 2006). The function of scaffolds is to direct the growth of cells seeded within the porous structure of the scaffold or of cells migrating from surrounding environments. The majority of mammalian cell types are anchorage-dependent resulting in dying if an adhesive surface is not provided. A successful scaffold should balance mechanical strength with biomolecular delivery capacity, providing an environment in which the regenerated tissue assumes function as the scaffold degrades (Hollister 2005). The success of BTE depends, to a large extent, on the performance of the 3D porous biodegradable scaffolds. The BTE scaffolds will fit into the anatomical defect, so they must have some strength and stiffness to keep their integrity at the initial in vivo stage. In $\mathrm{TE}$, the selection of appropriate biomaterials for scaffold production is very important because the scaffold properties are largely determined by the intrinsic properties of the materials. Also, the scaffold design and processing method will play an important role in the scaffold properties. 
Rapid prototyping (RP) is an excellent alternative compared with conventional methods as it can provide the consistency, flexibility in geometry and reproducibility in scaffold physical properties (Wiria et al. 2007). Among various RP technologies, selective laser sintering (SLS) has been found to be advantageous for TE scaffolds fabrication due to its ability to process a wide range of biocompatible and biodegradable materials (Chua et al. 2004). SLS appears to be useful primarily for bone implants production and it has been used to sinter poly(methyl methacrylate) coated calcium phosphate (Lee \& Barlow 1993) and hydroxyapatite reinforced polyethylene composites (known commercially as $\mathrm{HAPEX}^{\mathrm{TM}}$ ) for bone implants (Hao et al. 2006).

Disadvantages of SLS include a process more mechanically complex than most other RP techniques and powdery surface may complicate sterilization and cell culture (Venuvinod \& Ma 2004). As a layer additive technique, SLS parts also suffer from the stair-stepping problem. The first layers may need a base anchor to reduce thermal effects such as curling. For scaffold production, the resolution of SLS is limited by the laser beam diameter (spot size) and the particle size. Due to heat dissipation, particles outside the laser scan path are sometimes also fused ("growth" effect), causing an irregular boundary and roughness on the part surface (Yang et al. 2002); however, rough surface may attract some types of cells to attach and grow. Furthermore, when building porous scaffolds, the loose, unsintered powder trapped inside of the pores needs to be removed. The "growth" effect can make the cleaning of the loose powder difficult.

So far, only one hydrophobic biodegradable polymer, poly- $\varepsilon$-caprolactone (PCL), has been used to produce TE scaffold by conventional SLS machine because PCL is significantly less expensive and supplied in the fine powder form. Ciardelli et al. (2004) used a $\mathrm{CO}_{2} \mathrm{SLS}$ machine (SYNRAD model J48-5S, Italy) to fabricate scaffolds with the overall size of $15 \times 15 \times 3.3 \mathrm{~mm}$ (length $\mathrm{x}$ breadth $\mathrm{x}$ height) from PCL slurries. Those SLS scaffolds have a pore size of about $300 \mu \mathrm{m}$ (height) $\times 700 \mu \mathrm{m}$ (width). Williams et al. (2005) fabricated sintered PCL cylindrical porous scaffolds $(5.0 \mathrm{~mm}$ diameter, $4.5 \mathrm{~mm}$ height $)$ by Sinterstation ${ }^{\circledR} 2000$ at University of Michigan. The pore sizes of these scaffolds varied from $1.75 \mathrm{~mm}$ to $2 \mathrm{~mm}$. In vitro and in vivo results showed that laser sintered PCL scaffolds enhance tissue in-growth and their mechanical properties are within the lower range of trabecular bone. From the same group, Partee et al. (2006) optimized the SLS processing parameters for PCL powder using the systematic factorial experimental design method. The scaffolds were in the form of square prism with an overall size of $11.5 \times 14.2 \times 10.8 \mathrm{~mm}$ and a pore size of $2 \mathrm{~mm}$. The optimized PCL scaffolds showed designed porous channels and achieved a dimensional accuracy to within 3- 8\% of the design specifications and $94 \%$ of full density. Using optimal SLS processing parameters, BTE scaffolds were fabricated based on actual minipig and human condyle models.

Recently, Wiria et al. (2007) applied the SLS technique to first fabricate biodegradable composite scaffolds from physically blended PCL with micro-sized hydroxyapatite using Sinterstation ${ }^{\circledR} 2500$ (3D Systems). The scaffolds were in the form of circular disc with a diameter and thickness of $15 \mathrm{~mm}$ and $1 \mathrm{~mm}$ respectively. This overall size is good for fitting into a cell culture well. As compared to neat PCL, it was harder to sinter the PCL/HAp biocomposite blends. Similar observation was made by Fan et al. (2001) with other composite materials and they attributed the phenomenon to the increased viscosity of the composite materials. Chua et al. (2004) developed SLS scaffolds on poly(vinyl alcohol) (PVA) blended with micro-sized HAp, intending for craniofacial and joint defects repair. 
PVA was chosen due to the cheap price and the approximate particle size for SLS process. PVA is a hydrophilic biodegradable polymer which limits its use in cartilage and corneal tissue engineering (Sinha et al. 2007). Also, other materials, such as polyetheretherketone (PEEK) (Tan et al. 2003) and polyamide (Das et al. 2003), were used for building TE scaffolds. However, these materials are non-biodegradable, which limit their applications as stated earlier.

SLS has been developed primarily for industrial applications and it is still not financially viable to use the technology to produce TE scaffolds from a wide range of biomaterials due to limited availability of biomaterial powders suitable for SLS and extremely high costs of most biomaterial powders. With our success in modifying an existing Sinterstation ${ }^{\circledR} 2000$ SLS machine to allow small quantities of biopolymer powders to be processed (Lee et al. 2006) and preparation of poly(L-lactide) (PLLA) and PLLA/carbonated hydroxyapatite (CHAp) nanocomposite microspheres (Zhou et al. 2007), we were able to build porous PLLA and PLLA/CHAp TE scaffolds for further investigation.

The effects of sintering conditions; namely, laser power, part bed temperature and scan spacing, on the overall quality of PLLA scaffolds were first studied in this chapter. Then, the results were used to formulate a recommended list of sintering parameters for building good quality PLLA and PLLA/CHAp scaffolds. Finally, the structure and properties, e.g. porosity, compression properties, in vitro degradation behaviour and osteoconductivity (such as cell adhesion and growth), of these scaffolds were evaluated.

\section{Materials and Processing}

\subsection{Materials}

The PLLA used was 100L 1A with an intrinsic viscosity of $1.9 \mathrm{dL} / \mathrm{g}$ (Lakeshore Biomaterials, Birmingham, AL, USA). It was supplied in the form of macro-sized pellets, $1 \mathrm{~mm}$ in diameter and $3 \mathrm{~mm}$ in length, for conventional extrusion and moulding processes. The emulsifier used in our study was poly(vinyl alcohol) which was cold water soluble and with an average molecular weight of 30,000-70,000 (Sigma-Aldrich). CHAp nanospheres were synthesized by a nanoemulsion method (Zhou et al. 2008). Dichloromethane or methylene dichloride (DCM, Uni-Chem ${ }^{\circledR}$, Orientalab, China) was used as the organic solvent to dissolve PLLA.

\subsection{Preparation of PLLA microspheres}

PLLA microspheres were prepared using a normal oil-in-water $(\mathrm{O} / \mathrm{W})$ emulsion solvent evaporation technique. In brief, the PLLA was dissolved in DCM to form a solution first and then rapidly added to aqueous PVA solution and stirred for sometime to allow the solvent to evaporate. The hardened microspheres were centrifuged, washed three times with deionized water and lyophilized to obtain dry powder.

\subsection{Preparation of PLLA/CHAp nanocomposite microspheres}

The PLLA/CHAp nanocomposite microspheres were prepared using a solid-in-oil-in-water (S/O/W) emulsion solvent evaporation method (Zhou et al. 2007). Briefly, the CHAp nanospheres were dispersed in the PLLA-dichloromethane solution by ultrasonification (Barnstead Lab-Line ultrasonic cleaner, USA) and homogenization (Ultra-Turrax ${ }^{\circledR}$ T25 basic, 
IKA, Germany) to form an S/O nanosuspension. The nanosuspension was mixed with 1 $w \mathrm{t} \%$ PVA solution to form $\mathrm{S} / \mathrm{O} / \mathrm{W}$ emulsion. The resultant $\mathrm{S} / \mathrm{O} / \mathrm{W}$ emulsion was stirred overnight at $800 \mathrm{rpm}$ and then filtered, washed three times with de-ionized water, and freeze-dried to yield a white PLLA/CHAp biocomposite powder. Nanocomposite microspheres of $10 \mathrm{wt} \%$ CHAp in PLLA were used in the SLS process.

\subsection{Morphology characterization of microspheres}

The surface morphologies of the PLLA microspheres and PLLA/CHAp nanocomposite microspheres were examined using a scanning electron microscope (SEM, Stereoscan 440, Cambridge, UK). The internal structure of the composite microspheres was revealed by the focused ion beam (FIB) milling technique. A focused ion beam (Quanta 200 3D, FEI, USA) was applied to section the PLLA/CHAp composite microspheres for internal examination. The ion beam was tilted $52^{\circ}$ with respect to the electron beam and was only used for milling, not for imaging. The FIB milling process was carried out with a $\mathrm{Ga}^{+}$ion beam current of 3 $\mathrm{nA}$ and the acceleration voltage was $5 \mathrm{KeV}$. The milled faces were then polished with a low beam current of 0.3 and $0.1 \mathrm{nA}$ prior to SEM imaging.

\subsection{Modification of Sinterstation ${ }^{\circledR} 2000$ system}

In order to reduce the consumption of biomaterial powders for TE scaffold construction in the SLS process, modifications were made to an existing Sinterstation ${ }^{\circledR} 2000$ SLS machine (3D Systems, Valencia, CA, USA). The $\mathrm{CO}_{2}$ laser of the system has a maximum power output of 50 watts. The $\mathrm{CO}_{2}$ laser energy intensity across the beam diameter very nearly follows the Gaussian distribution (Nelson et al. 1993). A miniature sintering platform, which consisted primarily of a miniature build cylinder and two powder supply chambers, was designed, fabricated and installed in the build cylinder of the existing SLS machine (Lee 2006; Zhou et al. 2007; Zhou et al. 2008). The miniature build cylinder had a diameter of 50 $\mathrm{mm}$ and the movement of its base was directly linked to the base of the existing build cylinder of Sinterstation ${ }^{\circledR} 2000$. The two powder supply chambers were driven by two additional stepping motors beneath the miniature sintering platform. In the sintering processes, the original powder supply tanks of Sinterstation ${ }^{\circledR} 2000$ were empty and small amounts of biomaterial powder were fed from the miniature powder supply chambers. The roller positions were sensed and the signals were fed to an additional control panel which controlled the movement of stepping motors and the temperature of the small build cylinder. Other sintering parameters were controlled by the existing Sinterstation ${ }^{\circledR} 2000$ system and this would ensure good quality of the scaffolds built.

\subsection{Design of bone tissue engineering scaffolds}

The scaffold models were designed by an extrude-cut patterning method using SolidWorks ${ }^{\circledR}$ (version 2005). They had a tetragonal shape with the ratio of height $(\mathrm{H})$ to width $(\mathrm{W})$ or length (L) equal to 2 (ASTM D695-02a; ASTM D1621-04a). Rectangular channels were cut in all three dimensions to form 3D symmetrical scaffold models. This simple design contains the typical features and feature sizes found in BTE scaffolds (Partee et al. 2006). Type 1 model contained channels of size $0.8 \times 0.8 \mathrm{~mm}^{2}$ and Type 2 model contained channels of size $0.6 \times 0.6 \mathrm{~mm}^{2}$. The width of the solid pillar was kept at $0.3 \mathrm{~mm}$ in both Type 1 and Type 2 
models. The designed porosities for Types 1 and 2 were $78.4 \%$ and $70.0 \%$ respectively. The detailed design parameters of the scaffold models are listed in Table 1.

In SLS of porous scaffolds, the spot size of the laser beam is very important for building the small features of the scaffolds. The spot size or beam width is defined as the smallest diameter of the focused laser beam. According to the manufacturer of Sinterstation ${ }^{\circledR} 2000$ system, the spot size of this SLS machine is $0.018^{\prime \prime}(\sim 457 \mu \mathrm{m})$. To facilitate handling of the sintered scaffolds, a solid base $\left(9 \times 9 \times 3 \mathrm{~mm}^{3}\right)$ was incorporated in the scaffold design. If this base was not provided, the first few porous layers would tend to warp significantly, affecting the overall quality of the scaffolds (Partee et al. 2006).

In order to speed up production and to produce scaffolds with similar quality for tests, multiple scaffold models were assembled based on the single scaffold models. Four and nine models were assembled. Then, the data file was exported in an STL format and transferred to the Sinterstation ${ }^{\circledR} 2000$ system for the sintering process.

\begin{tabular}{|c|c|c|c|c|}
\hline Type & $\begin{array}{c}\text { Overall Size } \\
\left(\mathrm{mm}^{3}\right)^{*}\end{array}$ & $\begin{array}{c}\text { Channel Width } \\
(\mathrm{mm})\end{array}$ & $\begin{array}{c}\text { Pillar Width } \\
(\mathrm{mm})\end{array}$ & $\begin{array}{c}\text { Porosity } \\
(\%)\end{array}$ \\
\hline 1 & $8 \times 8 \times 16$ & 0.8 & \multirow{2}{*}{0.3} & 78.4 \\
\hline 2 & $6.6 \times 6.6 \times 13.2$ & 0.6 & & 70.0 \\
\hline
\end{tabular}

Table 1. Design parameters of porous bone tissue engineering scaffolds.

\subsection{Production of 3D porous scaffolds by modified Sinterstation ${ }^{\circledR} 2000$ system}

The build orientation (angle between the laser scanning direction and "L" dimension of the scaffold) was $45^{\circ}$. Significant variation in density and anisotropic properties were found in DuraForm $^{\mathrm{TM}}$ polyamide (a common SLS material) parts built in $00^{\circ}$ and $90^{\circ}$ orientations (Caulfield et al. 2007). The $45^{\circ}$ build orientation was chosen to reduce the anisotropy, also it was found to be effective in reducing warpage of porous scaffolds (Lee et al. 2004).

In SLS, the laser energy density (ED) level significantly affects the scaffold properties. The ED level is a measure of the amount of energy supplied to the powder particles per unit area of the powder bed surface. The relationship between ED and laser power $(\mathrm{P})$, scan spacing (SS) and beam speed (BS) can be expressed by the following equation (Nelson et al. 1993):

$$
E D=\frac{P}{S S \times B S}
$$

It is obvious that too low a laser power will render low strength or even incomplete sintering of the scaffold, while too high a laser power will cause the biopolymer to degrade and the scaffold to warp due to high residual stresses. Scan spacing (SS) means the distance between two parallel laser scans during a fill. In this study, the beam speed (BS) was fixed at $1257 \mathrm{~mm} / \mathrm{s}$ and the effects of laser power, scan spacing and part bed temperature (PBT) were investigated. Prior to this study, DuraForm ${ }^{\mathrm{TM}}$ polyamide was used as the reference material for initial settings of the sintering parameters (Lee 2006). After some trials, a workable set of sintering parameters was obtained for PLLA and PLLA/CHAp nanocomposite as shown in Table 2. Fig. 1 shows the SLS process in progress. Four scaffold bases were being sintered and the powder used was a PLLA/CHAp nanocomposite. Also, the powder delivery appeared to be smooth during the sintering process. The production time for one batch of scaffolds was about 2.5 hours. 


\begin{tabular}{|l|l|l|}
\hline Sintering Condition & PLLA & PLLA/CHAp \\
\hline Scan Spacing $(\mathrm{mm})$ & $0.15-0.21$ & $0.15-0.21$ \\
\hline Part Bed Temperature $\left({ }^{\circ} \mathrm{C}\right)$ & $30-40$ & $30-60$ \\
\hline Layer Thickness (mm) & 0.10 & 0.10 \\
\hline Roller Speed (mm/s) & 127 & 127 \\
\hline Scan Speed (mm/s) & 1257 & 1257 \\
\hline Stepping Motor Delay (ms) & 120 & 160 \\
\hline Fill Laser Power $(\mathrm{W})$ & $11-15$ & $11-19$ \\
\hline
\end{tabular}

Table 2. Recommended sintering conditions for PLLA and PLLA/CHAp microspheres.

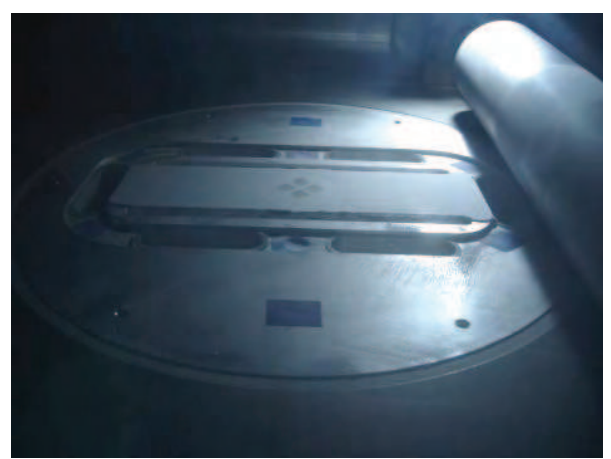

Fig. 1. Selective laser sintering of PLLA/CHAp powder in progress.

\subsection{Characterization of 3D porous laser sintered PLLA and PLLA/CHAp nanocomposite scaffolds}

\subsubsection{Porosity determination}

The scaffold porosity was determined using a specific gravity measurement kit and an electronic balance (Shimadzu, AW220, Japan). The detailed procedures and calculation were reported previously (Zhou et al. 2007).

\subsubsection{Compression test}

Compressive properties of the sintered scaffolds were determined using a MicroTester (Instron 5848, USA) with a load cell of $100 \mathrm{~N}$. The crosshead speed was $0.5 \mathrm{~mm} / \mathrm{min}$. The compressive modulus was determined from the initial linear region of compressive stressstrain curve. The compressive yield strength was determined from the first point on the stress-strain curve at which an increase in strain was observed without an increase in stress. The compressive modulus and yield strength for any given set of specimens were obtained by an average of five measurements and expressed as mean \pm standard deviation (SD). 


\subsubsection{In vitro degradation test}

Specimens containing 4 sintered layers cut from the sintered scaffolds were used in degradation test. The test specimens were accurately weighed, numbered and sterilized by $70 \%$ ethanol. The specimens were incubated at $37^{\circ} \mathrm{C}$ for $1,3,6$ and 8 weeks in phosphate buffered saline (PBS) solution ( $\mathrm{pH}$ 7.4). The PBS solution was changed fresh once a week. At weeks $1,3,6$, and 8 , three samples of each type of scaffold were removed and rinsed with de-ionized water 3 times and then air dried at room temperature. The level of degradation was assessed macroscopically in terms of weight loss and change in compressive properties. The results reported are averages of three measurements. The weight loss $(W L)$ after in vitro degradation was calculated by the following equation:

$$
W L(\%)=\left(W_{0}-W_{t}\right) / W_{0} \times 100
$$

where $W_{0}$ and $W_{\mathrm{t}}$ are specimen weights before and after degradation respectively.

\subsubsection{In vitro cell culture}

Human osteoblast-like Saos-2 cells harvested from patients in the Department of Orthopedics and Traumatology (O\&T), the University of Hong Kong were used in this research. The cells were cultured and proliferated in a new cell culture plate for one day prior to seeding. The scaffolds were sterilized by immersion in $70 \%$ ethanol for 1 day (Wiria et al. 2007). After sterilization, the scaffolds were washed and immersed in PBS for 1 day. Cells were trypsinized out of the plate at $37{ }^{\circ} \mathrm{C}(1 \mathrm{ml}$ trypsin to 1 plate/bottle), $5 \mathrm{ml}$ culture medium was added to stop trypsin action, and calculated using haemocytometer. $1 \times 10^{5}$ cells $/ \mathrm{mL}$ were added to each scaffold and allowed to attach to the matrix for $30 \mathrm{~min}$ before adding enough medium to submerge the scaffolds (Borden et al. 2003). The medium was changed every 3 days. Cell culture was allowed to continued for 7 and 14 days (Shen et al. 2006). Then, the scaffolds were transferred for SEM examination after fixation with glutaraldehyde solution.

\section{Results and Discussion}

\subsection{Morphology of PLLA and PLLA/CHAp microspheres}

Some PLLA microspheres and PLLA/CHAp nanocomposite microspheres are shown in Fig. 2 (a) and (b), respectively. Both types of microsphere exhibited a generally similar range of particle sizes between 5 and $30 \mu \mathrm{m}$ and which were suitable for SLS process. The pure PLLA microspheres appeared very smooth while some CHAp nanospheres were found partially embedded on the PLLA/CHAp nanocomposite microspheres and this may impart bioactivity (osteoconductivity) for the scaffolds built. Fig. 2 (c) shows the FIB-milled section of a PLLA/CHAp composite microsphere. The CHAp nanospheres were generally well distributed both on and inside the microsphere, forming a nanocomposite structure. The rough surfaces of the nanocomposite microspheres likely facilitate cell attachment. In addition, the nanocomposite microspheres flowed more easily than the pure PLLA microspheres, making powder deposition easier during SLS process. 

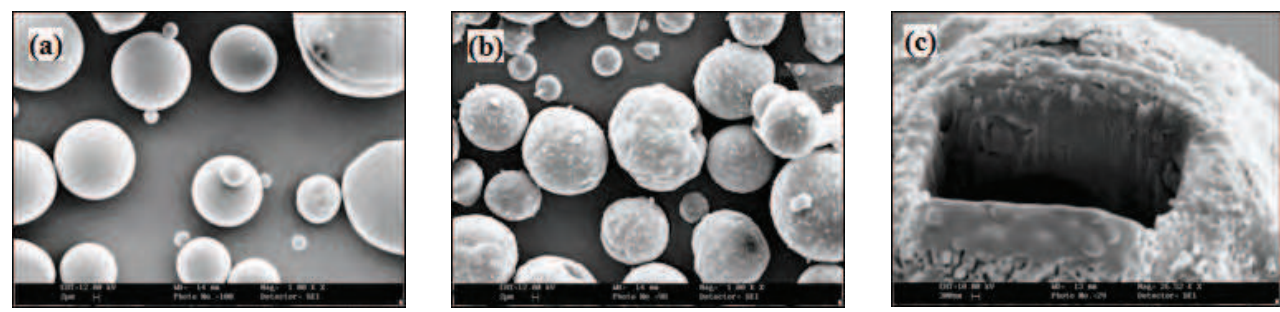

Fig. 2. SEM images of microspheres: (a) PLLA, (b) PLLA/CHAp nanocomposite and (c) an FIB-milled section of a PLLA/CHAp nanocomposite microsphere.

\subsection{Effects of sintering parameters on scaffold structure}

\subsubsection{Effect of laser power}

Sintering work was carried out on both PLLA and PLLA/CHAp microspheres covering a range of fill laser power $(\mathrm{P})$ from $7 \mathrm{~W}$ to $19 \mathrm{~W}$. It was found that when $\mathrm{P}<7 \mathrm{~W}$, the scaffolds could not take shape and they fell apart during handling. Fig. 3 (a) is an SEM image showing a surface layer of a Type 1 PLLA scaffold sintered at $19 \mathrm{~W}$. It can be seen that the struts of the scaffold were well sintered. The designed dimension of the struts was $300 \mu \mathrm{m}$, however, the actual size turned out to be $490 \pm 33 \mu \mathrm{m}$. The discrepancy was due to "growth", which is a common phenomenon in SLS. When the laser penetrates beyond the design scan range, some polymer particles are either fully or partially melted and adhere onto the designed scaffold structure. Fig. 3 (b) shows a high magnification SEM image of a design pore area. Although the trapped PLLA microspheres still appeared to be in powder form, they were in fact partially fused together and necks were formed between them. It was quite possible when sintering with a high laser power, the temperature of the design pore areas increased to near or even above the melting point of the polymer and caused necking of the microspheres. These trapped microspheres could not be removed by the air-pressure gun and would therefore defeat the function of the porous scaffolds as originally designed. Obviously, a laser power of $19 \mathrm{~W}$ was too high and it should be adjusted down so that the powder in the pores could be removed. Finally, a proper set of sintering parameters was obtained and it is shown in Table 2.
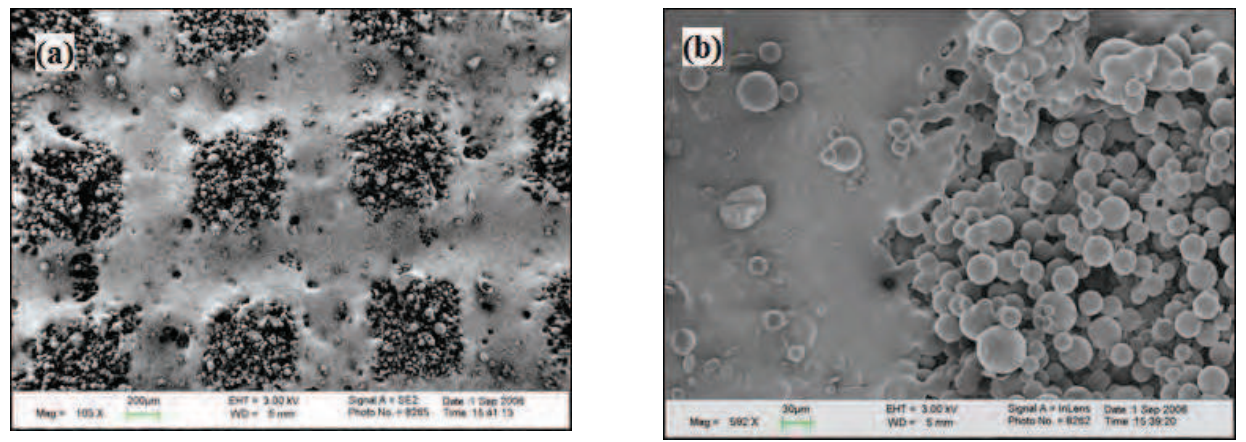

Fig. 3. SEM images of a Type 1 PLLA scaffold sintered at 19W: (a) low magnification showing the overall surface layer structure and (b) high magnification showing necking of PLLA microspheres in the design pore area (on the right side of image). 


\subsubsection{Effect of part bed temperature}

Fig. 4 shows the effect of part bed temperature (PBT) on the structure of scaffolds built from the pure PLLA microspheres. When PBT was within the range as shown in Table 2, the unsintered powder within the pores could be removed easily by an air gun and the resultant scaffolds exhibited a distinctive porous structure (sample a). When PBT was higher than the recommended range however it was difficult to remove all the unsintered powder from the pores (sample b). In normal SLS processes, PBT should be set near the $\mathrm{T}_{\mathrm{g}}$ of amorphous polymers and just below the $\mathrm{T}_{\mathrm{m}}$ of semi-crystalline polymers, at the time the laser only provides small amounts of extra heat energy for powder fusion. Too high a PBT caused the powder in the pores to partially fuse with the design structure and difficult to be removed. On the other hand, too low a PBT would result in low strength of the scaffolds and they tended to fall apart during handling.

\subsubsection{Effect of scan spacing}

Fig. 5 shows the effect of scan spacing (SS). Too small an SS would result in excessive amount of laser energy to be deposited on the powder bed surface and cause blocking of the pores (sample a). When SS was too large, the laser energy density became too low for complete sintering of the scaffold structure and hence it could not take shape. In general, extreme values of the processing parameters should be avoided in order to obtain a desirable porous structure (sample b).

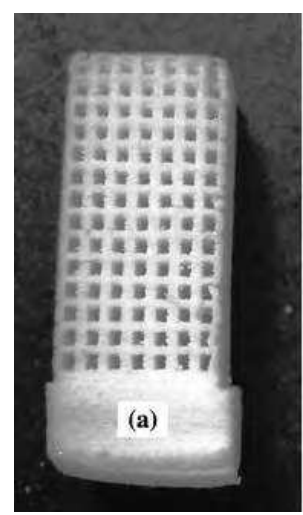

Fig. 4. Effect of part bed temperature (PBT) on structure of PLLA porous scaffolds: (a) $\mathrm{PBT}=35^{\circ} \mathrm{C}$ and $(\mathrm{b}) \mathrm{PBT}=50^{\circ} \mathrm{C}$.
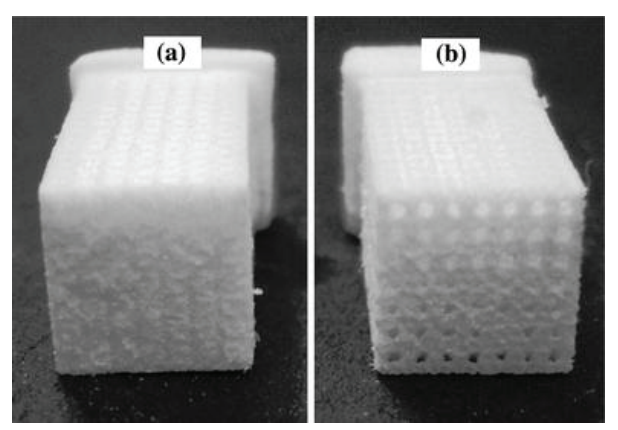

Fig. 5. Effect of scan spacing (SS) on structure of PLLA porous scaffolds: (a) SS = $0.08 \mathrm{~mm}$ and $(\mathrm{b}) \mathrm{SS}=0.18 \mathrm{~mm}$. 

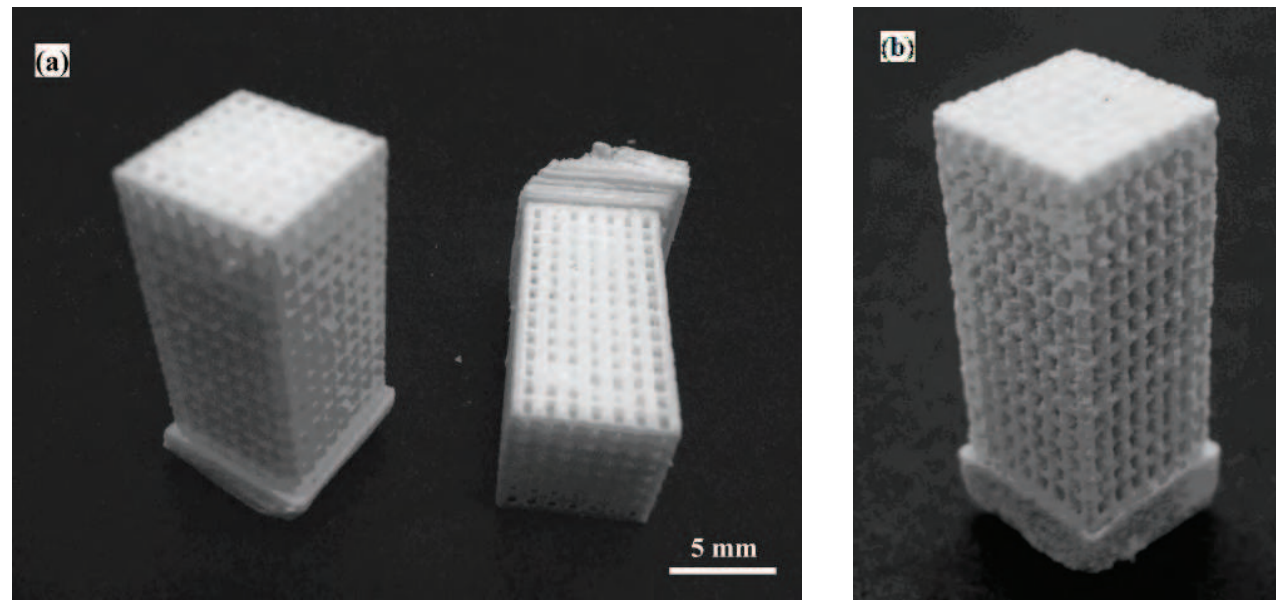

Fig. 6. Selective laser sintered porous scaffolds (Type 1) from (a) PLLA microspheres and (b) PLLA/CHAp nanocomposite microspheres.

\subsection{Morphology of scaffolds built under recommended conditions}

\subsubsection{General appearances}

The general appearances of the PLLA and PLLA/CHAp porous scaffolds built under the recommended conditions are shown in Fig. 6 (a) and (b), respectively. After removal of the excessive powder, the pores could be easily recognized and the layers were firmly attached together. Such scaffolds were used for subsequent structural, mechanical, degradation and biological assessments.

\subsubsection{Layer morphology}

Fig. 7 shows the typical layer morphologies of the PLLA and PLLA/CHAp scaffolds sintered under the recommended conditions. It can be seen that the PLLA microspheres were well fused in the scanned areas, Fig. 7 (a). Nevertheless, the sintered material was not fully dense and some very fine pores were present, resulting in a porous structure possessing a combination of meso-pores (due to design) and micro-pores (due to incomplete fusion of the sintered material). This structure likely facilitates the flow of body fluid and promotes nutrition and metabolism waste exchange, and hence is more beneficial to cell growth than a scaffold with only micro-pores, for example the PCL/HAp disc scaffolds reported by Wiria et al. (2007). Also, the powder preparation methods used in the two studies were different. In this study, the nanocomposite was prepared by emulsion microencapsulation method and the nano-sized CHAp particles were well encapsulated in the PLLA/CHAp microspheres even before sintering, on the other hand the PCL/HAp composites used by Wiria et al. (2007) were physically blended. Furthermore, the biopolymers used in the two studies were different; therefore, the scaffolds produced likely have different in vitro and in vivo properties. In the laser sintered scaffolds built by Williams et al. (2005) with PCL, the smallest pore size reported was $1.75 \mathrm{~mm}$ in diameter. As can be seen from Fig. 7 (b), the pores size of the PLLA scaffold is around $200 \mu \mathrm{m}$ which is much 
smaller than the laser spot size of $457 \mu \mathrm{m}$. This study showed that it is possible to build scaffolds with pore sizes below the limitation of laser beam width.

When the PLLA and PLLA/CHAp scaffolds were sintered with the respective conditions as shown in Table 2, there was no problem in removing the excessive trapped powder from the pores. For the PLLA scaffolds, a low pressure air gun was needed to remove the excessive powder. The layers were generally well preserved afterward and the pores of the scaffolds could be clearly identified. For the PLLA/CHAp nanocomposite scaffolds, the loose powder could be shaken off by hand. It has been reported in the literature that removing the excessive powder from the pores is a major obstacle for porous scaffold production using the SLS process (Tan et al. 2003). Here, the PLLA/CHAp nanocomposite microspheres seem to offer a solution to the problem provided the sintering conditions are properly set.

There is a difference between the design and actual pore sizes. When the design pore size was $0.8 \mathrm{~mm}$, the actual pore size of sintered scaffolds was only about $438 \pm 52 \mu \mathrm{m}$ as shown in Fig. 7 (a). In Type 2 scaffolds, the pore size was even smaller compared with the design pore size (Fig. 7 (b)). Obviously the reduction in pore size was a result of "growth" which was caused by the penetration of the laser energy beyond the design scan area. Therefore, it is important to take into consideration the effect of "growth" in designing the pore size of the scaffolds built by SLS.
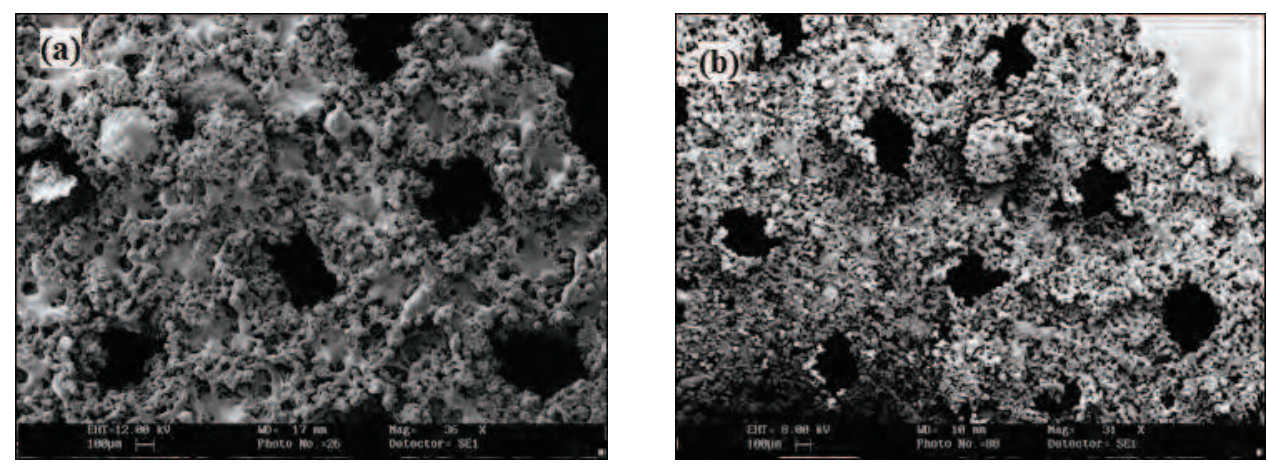

Fig. 7. SEM images showing the layer structures of (a) PLLA scaffold (Type 1) and (b) PLLA/CHAp nanocomposite scaffold (Type 2); sintering condition: $\mathrm{P}=15 \mathrm{~W}$.

\subsubsection{Comparison of fusion behavior}

It can also be seen from Fig. 8 (a) and (b) that the degree of fusion of the PLLA/CHAp nanocomposite powder was lower than that of the pure PLLA powder. This could be explained by the increased viscosity of the composite material. It has been postulated that a filled polymer will sinter at a different rate as the same polymer without filler, in inverse proportion to the viscosities of the filled and unfilled materials (Childs \& Tontowi 2001). Fan et al. studied the material movement and fusion behavior of $\mathrm{SiO}_{2}$ and glass sphere (GS) filled TrueForm ${ }^{\mathrm{TM}}$ composites during selective laser sintering (Fan et al. 2001; Fan 2003). They found that for a given volume fraction of the additive, a smaller particle size of the fillers in dry mixed polymer composites would obstruct fusion of molten polymer particles more significantly and result in weak parts. The embedded fillers increased the material viscosity and adversely affected the densification of the powder bed. Also the CHAp 
nanoparticles on the powder surface might act as a barrier against fusion. Another possible reason for the lower degree of fusion of the PLLA/CHAp nanocomposite microspheres was the relatively high specific heat capacity of hydroxyapatite. According to Cruz et al. (2005), the molar heat capacity $\left(\mathrm{C}_{\mathrm{p}, \mathrm{m}}\right)$ of HAp is $694 \pm 68 \mathrm{~J} \mathrm{~mol}^{-1} \mathrm{~K}^{-1}$ in the temperature range 298$1298 \mathrm{~K}$, which is much higher than that of PLLA, from 145.4 to $156.7 \mathrm{~J} \mathrm{~mol}^{-1} \mathrm{~K}^{-1}$ in the temperature range from $332.5 \mathrm{~K}\left(\mathrm{~T}_{\mathrm{g}}\right)$ to $480 \mathrm{~K}\left(\mathrm{~T}_{\mathrm{m}}\right)$ (Pyda et al. 2004; Malmgren et al. 2006). Therefore, CHAp (a hydroxyapatite based ceramic) can be regarded as a huge energy reservoir to absorb laser energy. So the amount of laser energy input into the PLLA matrix of the composite powder was reduced, resulting in a lower degree of fusion of PLLA/CHAp particles.

Some PLLA microspheres were present in Fig. 8 (a), and most probably bonded to the surface during powder deposition when the sintered material was still hot; as a result they could not be completely removed by the compressed air gun. Such microspheres would increase the surface roughness of the scaffold and this might be advantageous to cell attachment. Underneath the microspheres, the polymer was generally well sintered; nevertheless, some micro-pores were present due to incomplete fusion. This renders a porous structure consisting of both meso-pores (by design) and micro-pores.
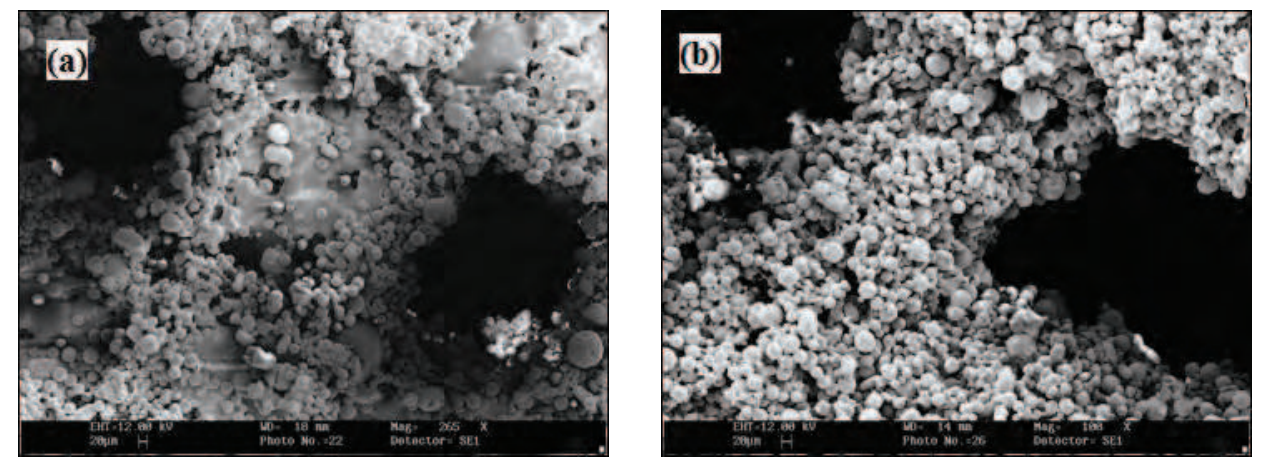

Fig. 8. Comparison of fusion behavior of laser sintered scaffolds (Type 1): (a) PLLA and (b) PLLA/CHAp; sintering condition: $\mathrm{P}=15 \mathrm{~W}$.

\subsubsection{Importance of meso-scale feature}

As seen above, the scaffolds have similar meso-scale feature compared with some recently developed scaffolds. The 3D channels created into the scaffolds played an important role in cell attachment and proliferation and enhanced nutrient transfer and waste exchange (Rose et al. 2004; Mahoney et al. 2005). A common problem encountered with scaffolds based tissue engineering strategies is the rapid formation of tissue on the outer edge of the scaffold whilst the tissue in the centre becomes necrotic. A way of addressing this problem is to incorporate a specific meso-scale feature design into the scaffold to improve nutrient and cell transfer to the scaffold centre. Recently, Rekow et al. (2006) reviewed that scaffold features at different length scales can have dramatic influences on bone tissue response. Nano-scale features $(<1 \mu \mathrm{m})$ of the scaffolds may control interactions at the protein level and thus influence the biocompatibility. Micro-scale scaffold features $(1-20 \mu \mathrm{m})$ will modulate cell behavior, affecting both the type of cells that adhere to a scaffold surface. 
Meso-scale features (200-1000 $\mu \mathrm{m})$ will influence the structural support of the scaffold and the amount of bone that can develop. The meso-scale has been largely overlooked. Macroscale features $(>1 \mathrm{~mm})$ will define the anatomic shape.

Meso-scale scaffold feature may be achieved by inserting 3D interconnected channels into the body of a scaffold creating a porous structure with different length scales. Frosch and coworkers (2002) assessed the infiltration of human osteoblasts into a range of channel diameters (from 300 to $1000 \mu \mathrm{m}$ ) within titanium implants containing no other form of porosity. They found that cell ingrowth and subsequent matrix formation increased with increasing channel diameter up to $600 \mu \mathrm{m}$; however matrix production was sub-optimal in the $1000 \mu \mathrm{m}$ channel. $\mathrm{Xu}$ et al. (2007) pointed out that porous scaffolds should have branched channels to ensure uniform cell feeding and even flow of culture medium through the scaffold to promote uniform cell attachment and growth. Precise control of scaffold architecture (e.g. porosity, pore geometry, size, interconnectivity, orientation, and branching) is needed to optimize the scaffold properties for nutrient diffusion, cell growth and tissue regeneration.

\subsection{Properties of scaffolds built under recommended conditions}

\subsubsection{Effect of laser power on porosity}

The porosities of the sintered scaffolds were determined based on the measurement of specific gravity and plotted in Fig. 9 as a function of fill laser power. As expected, the porosities decreased with increasing laser power for both Type $1(0.8 \mathrm{~mm}$ pores $)$ and Type 2 (0.6 mm pores) PLLA and PLLA/CHAp scaffolds. The relationships were almost linear within the recommended range of laser power (see Table 2). All measured porosities of the scaffolds were below the design values. The phenomenon was due to excessive "growth" (especially when sintering was done at high laser power) and the difficulty in removing the unwanted powder from the pores (especially for Type 2 scaffolds). Nevertheless, the measured and design porosities were relatively close for scaffolds sintered at a fill laser power of $11 \mathrm{~W}$, i.e. the lowest value within the recommended range. Apparently, a lower laser power is preferred in terms of controlling the porosity. Furthermore, it is noted that the difference between the measured and design porosities of PLLA scaffolds is much larger than that of the PLLA/CHAp scaffolds, especially in Type 2 scaffolds (i.e. with a smaller design pore size). This indicates that, in order to control the porosity, one not only has to consider the sintering condition, but also the material used and scaffold design. In this respect, PLLA/CHAp seems to be a better material choice than pure PLLA. This can be attributed to its higher viscosity and microsphere surface morphology (containing high content of CHAp nanoparticles) which tend to limit the amount of "growth" and therefore the unsintered powder can be removed more easily. However, it should be pointed out that such material characteristics may affect the fusion behavior (see Fig. 8) and other scaffold properties which will be discussed later. 


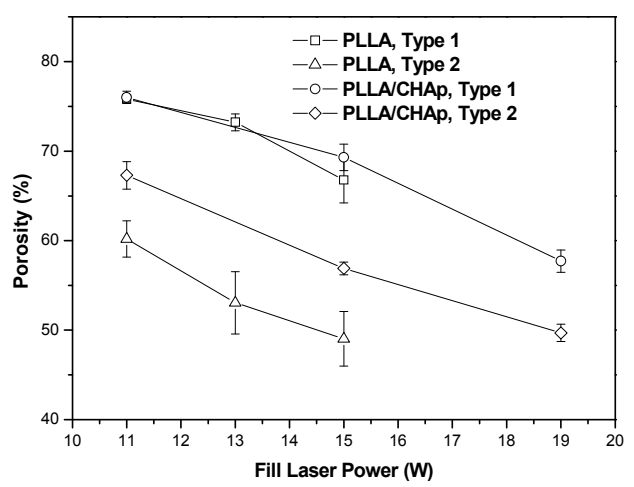

Fig. 9. Effect of fill laser power on porosity of selective laser sintered PLLA and PLLA/CHAp scaffolds, the design porosities of Type 1 and Type 2 scaffolds are $78.4 \%$ and $70.0 \%$, respectively.

\subsubsection{Effect of laser power on compression properties}

Models describing the mechanical behavior of cellular solids such as open-cell foams are well developed (Harley et al. 2007). A typical stress-strain curve for low-density, elastomeric open-cell foam in compression is characterized by three distinct regimes: a linear elastic regime which corresponds to strut bending, a collapse plateau regime which corresponds to strut buckling and pore collapse and a densification regime which corresponds to complete pore collapse throughout the material. Lee (2006) reported two modes of failure of porous selective laser sintered scaffolds built from DuraForm ${ }^{\mathrm{TM}}$ PA. Buckling was found to occur when the vertical struts had a higher slenderness ratio or larger pore size, and the scaffold collapsed layer by layer almost vertically. Meanwhile shearing occurred with a lower slenderness ratio of the vertical struts, and the scaffold was compressed into an "S" shape. In this study, shearing was found to be the predominant mode of failure and the scaffolds were compressed into an "S" shape. Fig. 10 shows a typical compressive stress-strain curve of Type 1 PLLA/CHAp scaffolds. It exhibits three regimes which, to a large extent, resemble those commonly observed in cellular structures (Gibson \& Ashby 1997). A similar linear elastic regime first appears, from which the compressive modulus can be measured. Beyond this zone, unlike the smooth plateau for low-density, elastomeric open-cell foam, a peaky plateau regime is observed. This peaky plateau can be attributed to sequential collapses of layers due to shearing. Each peak involves a number of layers. Once the shear deformation reaches a critical value, the vertical struts may break causing the compressive load to drop while the heavily deformed layers are collapsing. When all the layers have collapsed, further compressing will give rise to the final regime of densification with further increase of stress. 


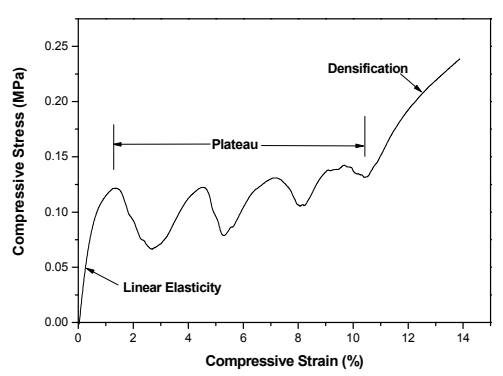

Fig. 10. Typical compressive stress-strain curve of Type 1 PLLA/CHAp scaffold (pore size $=0.8 \mathrm{~mm})$, sintered at $15 \mathrm{~W}$.

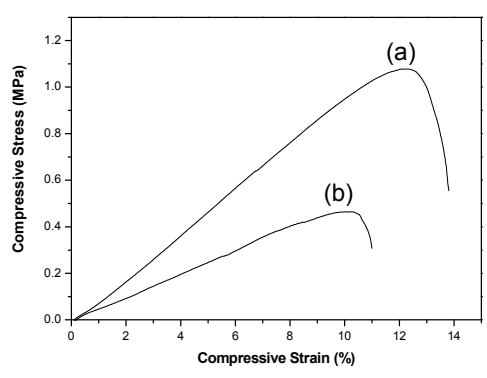

Fig. 11. Typical compressive stress-strain curves of 4-layer PLLA scaffolds (Type 1): (a) sintered at $15 \mathrm{~W}$ and (b) sintered at $13 \mathrm{~W}$.

It was found that sintered scaffolds consisting of 4 layers were sufficient for investigation of the initial linear elastic regime. Therefore, 4-layer specimens were later used to determine the compressive modulus and strength of the different scaffold types in order to save material. Fig. 11 shows the typical compressive stress-strain curves of two such PLLA scaffolds sintered at different laser power. The initial elastic regimes appear relatively linear. It can be seen that the scaffold sintered at $15 \mathrm{~W}$ has a higher compressive yield strength and strain than that sintered at $13 \mathrm{~W}$. Furthermore, the compressive yield strength and strain of the PLLA scaffolds appear to be much higher than those of the Type 1 PLLA/CHAp scaffold shown in Fig. 10.

The overall effects of fill laser power on the compressive yield strength and modulus of the PLLA and PLLA/CHAp scaffolds are shown in Figs. 12 and 13 respectively. It is clear that the compressive yield strength increases with increasing fill laser power. Besides, the compressive yield strength is also affected by both the scaffold type and material. The porosity and fusion behavior are two major factors affecting the mechanical properties of the selective laser sintered scaffolds. For the same material, either PLLA or PLLA/CHAp, Type 2 scaffolds have a lower porosity and hence the compressive yield strength is higher. For the same scaffold type, PLLA gives higher compressive yield strength and modulus than the PLLA/CHAp nanocomposite, and this is mainly due to the better fusion behavior of the pure polymer. Apart from improving the biological property, the ceramic phase (CHAp nanospheres) was added in an attempt also to improve the mechanical property of the scaffolds. On the contrary, the results in Figs. 12 and 13 show a reduction in compressive properties under the current sintering conditions. Perhaps, some sort of post-sintering processing is required to consolidate the structure of the PLLA/CHAp scaffolds before use. 


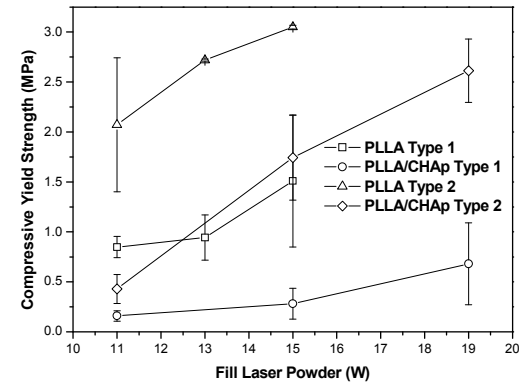

Fig. 12. Effect of fill laser power on the compressive yield strength of laser sintered scaffolds.

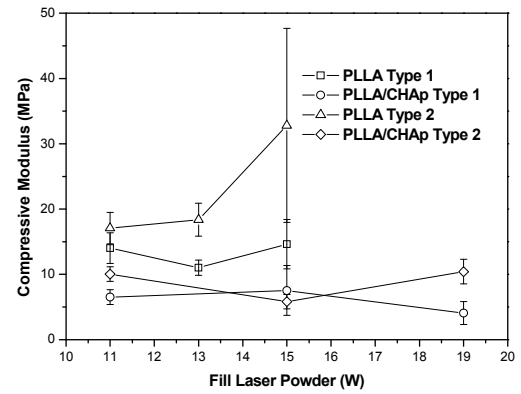

Fig. 13. Effect of fill laser power on the compressive modulus of laser sintered scaffolds.

Mechanical property is an important requirement for scaffold use in bone tissue engineering. As templates to guide tissue regeneration, scaffolds need to have enough mechanical strength in order to retain their shape during in vitro and in vivo applications. Further requirements for scaffold mechanical properties will differ from applications. For example, for regeneration of trabecular bone, the scaffold will deliver cells and growth factors to the graft site, to mimic cancellous bone grafting where the mass of bony spicules and marrow possess no inherent mechanical strength (Guan \& Davies 2004). In such strategy, the scaffold only needs to be strong enough to maintain its dimensional integrity during cell culture. Human cancellous bone (wet condition) has a reported compressive modulus and strength range of 20-900 $\mathrm{MPa}$ and 1-15 $\mathrm{MPa}$, respectively. Human cortical bone (wet condition) has a reported compressive modulus and strength range of 5-20 GPa and 100-200 MPa, respectively (Athanasiou et al. 2000; Kofron et al. 2007). In this study, the laser sintered PLLA scaffolds have a compressive modulus and strength range of 15-30 MPa and 1-3 MPa, respectively; the laser sintered PLLA/CHAp scaffolds have a compressive modulus and strength range of 4-10 MPa and 0.2-2.5 MPa, respectively. It indicates that after optimization of the sintering conditions, the SLS scaffolds may achieve mechanical properties suitable for cancellous bone tissue engineering application. Guan \& Davies (2004) fabricated a unique composite scaffold for bone tissue engineering by combining poly(lactide-co-glycolide) (PLGA) with bioresorbable calcium phosphate cement particles through the process of particle fusion and phase separation/particle leaching. The scaffold is characterized by a highly interconnected macro-porosity, with macro-pores of 0.8-1.8 mm and porosities ranging from 81 to $91 \%$. The addition of calcium phosphate to the matrix prevented scaffold collapse, when placed in media or seeded with cells; however, the compressive strength of the scaffold $(0.16 \mathrm{MPa})$ and modulus $(6-8 \mathrm{MPa})$ are below that of cancellous bone. Williams et al. (2005) fabricated 3D PCL scaffolds by SLS with a pore size $1.75-2.5 \mathrm{~mm}$ and porosity $37-55 \%$. The cylindrical scaffolds possessed a compressive modulus of 52-67 MPa and yield strength of 2-3.2 MPa. Polymeric scaffolds fabricated by SLS demonstrated lower mechanical properties when compared with other techniques such 
as the heat sintered microsphere scaffolds. On the other hand, SLS can fabricate complex scaffolds more easily than microsphere heat sintering method. Kofron et al. (2007) fabricated PLGA/HAp microsphere scaffolds by heat sintering and those scaffolds have a compressive modulus of $100-200 \mathrm{MPa}$ and strength of $20-80 \mathrm{MPa}$ controlled by sintering time and temperature. The difference of mechanical performance for laser sintered microspheres and heat sintered microspheres is due to the energy sources and scaffold design. Heating will generally cause polymer to adhere or melt more easily than laser sintering. In Laurencin's group (Lu et al. 2003), they used 100-200 $\mu \mathrm{m}$ PLGA or PLGA/bioactive glass microspheres to form scaffolds. The average porosity and pore diameter of the PLGA and PLGA/bioactive glass scaffolds were 31 and $43 \%$ and 116 and $89 \mu \mathrm{m}$. Thus a lower porosity will give scaffolds higher compression properties. The mechanical properties of the scaffolds are highly dependent on the geometry too. In clinical applications, scaffold geometry will depend on the anatomical location of the injury.

\subsubsection{In vitro degradation}

The weight loss of PLLA and PLLA/CHAp scaffolds over 2 months of in vitro degradation test in PBS are shown in Figs. 14 and 15, respectively. In general, the weight loss increases with increasing degradation time and the scattering of data is quite large. The major loss in weight was due to removal of microspheres loosely bonded on the scaffold surface and within the pores, such as those shown in Fig. 8. For Type 1 PLLA scaffolds, Fig. 14 (a), the effect of fill laser power is not clear and the overall weight loss (over 2 months) is around 4$6 \%$ for all values of laser power used. Nevertheless, it is quite clear that for Type 1 PLLA/CHAp nanocomposite scaffolds, Fig. 14 (b), the degradation rate decreases with increasing laser power. This is expected as a higher laser power will produce a more compact structure of the scaffolds, reducing the contact between the phosphate buffered saline and the scaffold material. There is a slight trend of abnormal degradation behavior for Type 1 PLLA scaffolds as shown in Fig. 14 (a), i.e. the PLLA scaffolds sintered at a higher fill laser power suffering a higher weight loss than those sintered at a lower laser power. This anomaly was probably due to excessive "growth" under the higher laser power. Although the trapped PLLA microspheres could not be removed by the air-pressure gun, they might be detached from scaffold in PBS during the 2-month degradation test under continuous shaking.

When comparison is drawn between PLLA and PLLA/CHAp scaffolds sintered at $11 \mathrm{~W}$, the nanocomposite scaffolds suffered a much high degradation rate. One possible explanation to the phenomenon is that under this relatively lower laser power (lowest within the recommended range) and due to the poorer fusion behavior of the nanocomposite microspheres, there were a large number of very loosely bonded microspheres within the scaffolds. These microspheres would not survive the test and were detached out relatively quickly. When the laser power was increased to $15 \mathrm{~W}$, however, some of those loosely bonded microspheres became more securely bonded to the solid structure causing the weight loss to drop.

From Fig. 15 (a), Type 2 PLLA scaffolds are found to suffer a much bigger weight loss than and Type 1 PLLA scaffolds. Again, this can be attributed to the larger amount of loosely bonded microspheres being dislodged from the scaffolds structure during the degradation test. Since Type 2 scaffolds possessed smaller pores and therefore more such particles were expected to be trapped within the scaffolds even after the compressed air gun treatment. 
The results in Fig. 15 (b) are somewhat unclear. It is suspected that excessive "growth" and different degrees of damage caused during powder removal and degradation test might have contributed to the large variations in the test results.

In general, the degradation time of PLLA is around 2-3 years and there are four steps involved in the degradation process: (1) swelling and hydration of PLLA; (2) breakage of the ester bonds; (3) diffusion of the soluble degradation products; and (4) disappearance of the polymer scaffold struts (Gong et al. 2007). In this study, due to time limit, the degradation tests only lasted for 2 months. Primarily, only the first step was involved and the weight loss was mainly due to detachment of loosely bonded microspheres. There may be some swelling and hydration of PLLA involved too. With regard to the degradation mechanism of PLLA, the commonly held believe is that PLLA is a hydrolyzable polymer that follows a bulk degradation (Gong et al. 2007). The study by von Burkersroda et al. (2002) showed that all degradable polymers can undergo surface degradation or bulk degradation. The way a polymer matrix degrades all depends on the diffusion of water inside the matrix, the degradation rate of the polymer's functional groups and the matrix dimension. The dimension is an important factor. If a matrix is larger than a critical device dimension, it will undergo surface degradation; if not, it will be bulk degradation. Polyanhydrides were found to be surface degradation down to a size of approximately $10^{-4} \mathrm{~m}$ while poly( $\alpha$-hydroxy esters) matrices need to be larger than $10^{-1} \mathrm{~m}$ to lose their bulk degradation properties. The strut and microsphere sizes of the sintered PLLA and PLLA/CHAp scaffolds are all less than $0.1 \mathrm{~m}$ in this study which would show bulk degradation characteristics. The ester bonds in the backbone chain break randomly to generate carboxyl groups, which in turn autocatalytically accelerate the degradation reaction, resulting in an exponential (Park 1995) or linear (Gong et al. 2007) decrease of the molecular weight of a bulk PLLA material with degradation time. The intermediate degradation products are trapped inside the material before their molecular weights decrease to a critical value of about 1100 to be soluble in water. The loss of the precise shape of the tissue engineering scaffold after implantation is a common problem (Shieh et al. 2004). This study showed that the laser sintered scaffolds could maintain their original shapes after 2 months in vitro degradation which may be beneficial for implantation of the scaffolds in vivo. However, compared with the degradation in vitro, the degradation rate of the PLLA scaffolds in vivo was much faster (Dijk et al. 2002; Gong et al. 2007). The in vivo environment, including the easy exchange of substances, the enzymes and loading condition, is usually regarded to accelerate the degradation of the polymer scaffold. In vitro degradation of biodegradable implants has been commonly used to predict their in vivo behavior, but it is difficult to take all the in vivo environmental variables into account. In order to optimize the scaffolds for real tissue engineering applications, ideally in vivo experiments should be performed. However, such experiments involve animal tests and it is beyond the scope of this study. 
(a)

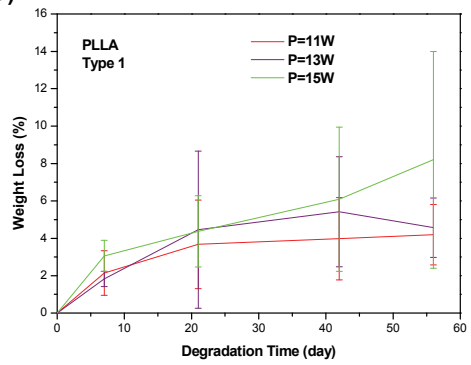

(b)

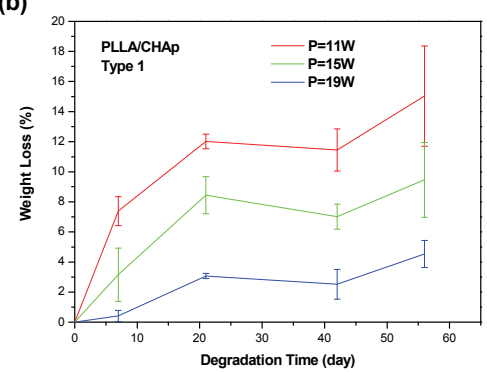

Fig. 14. Weight loss of porous laser sintered Type 1 scaffolds during degradation in PBS: (a) PLLA scaffolds and (b) PLLA/CHAp scaffolds; sampling size $n=3$.

(a)

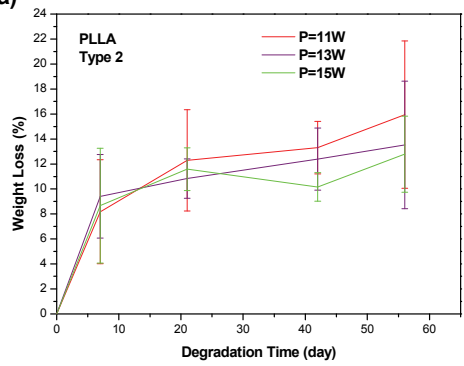

(b)

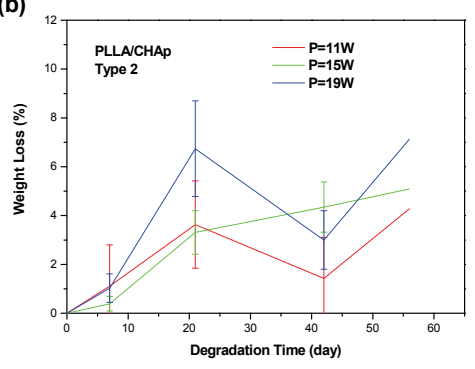

Fig. 15. Weight loss of porous laser sintered Type 2 scaffolds during degradation in PBS: (a) PLLA scaffolds and (b) PLLA/CHAp scaffolds; sampling size $\mathrm{n}=3$.

\subsubsection{Compression properties after in vitro degradation}

The compressive yield strength and modulus of the PLLA and PLLA/CHAp scaffolds were measured through the 2-month in vitro degradation test and the results are shown in Figs. 16 and 17. In general, the compression properties decreased with increasing degradation time. The modulus dropped more significantly within the first week of the degradation test and then followed by a more gradual decrease. This trend coincides with the rate of weight loss as shown in Figs. 14 and 15. Furthermore, it can be seen that the change of compressive modulus was much bigger than that of compressive strength. Similar effect was observed by Yang et al. (2006). One possible explanation was that the modulus was more dependent on the amount of loose particles trapped within the scaffold structure. When under compression, some of these particles were squeezed more tightly together giving a support to the scaffold structure, particularly at the early stage of the compression test in which the modulus was determined. Once these particles were removed after the degradation test there was a significant drop in the modulus. In comparison, compressive yielding of the scaffolds occurred at a later stage and under a more complex loading situation. Shearing and bending of the vertical struts would likely involve local tensile stresses and cracking. 
Under these circumstances, the loose particles trapped within the scaffold structure would not contribute significantly to the yield strength.
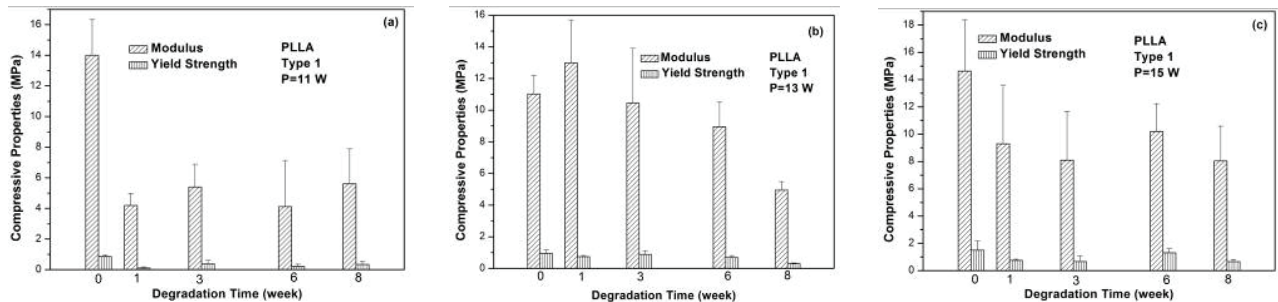

Fig. 16. Change of compression properties of Type 1 PLLA scaffolds produced by different laser powers during in vitro degradation.
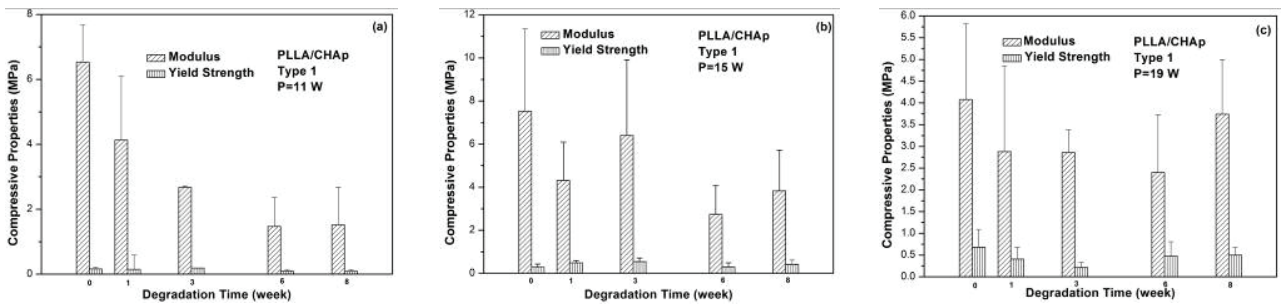

Fig. 17. Change of compression properties of Type 1 PLLA/CHAp scaffolds produced by different laser powers through in vitro degradation test.

\subsubsection{In vitro cell culture}

The cells used were Saos-2, the human epithelial-like osteosarcoma cell line. These cells are widely used in studies on bone cell differentiation, proliferation and metabolism and are known to be capable of bone production (Causa et al. 2006; Wiria et al. 2007). The Saos-2 cells possess several osteoblastic features and could be useful as a permanent line of human osteoblast-like cells and as a source of bone-related molecules. In vitro studies with these osteoblast-like cells have offered insights into the biological performance of bone implant materials. Figs. 18 and 19 show the SEM images of the cell-seeded Type 1 PLLA and PLLA/CHAp scaffolds respectively after culturing for 7 and 14 days. It can be seen that Saos-2 cells were able to attach to both scaffolds. However, the cells did not spread well on the PLLA scaffold surface and the outlines of many microspheres were still easily observable. In the case of the PLLA/CHAp scaffold, however, the cells were well spread and connected with each other covering most of the scaffold surface. Borden et al. (2003) attached human osteoblast cells on the heat sintered PLGA microsphere scaffolds. Their results, after culturing for 7 and 16 days, showed that the cells had bypassed the top surface of the microspheres and only formed a layer covering the surface of the microspheres within the pores. In another study on laser sintered PCL/HAp scaffolds (Wiria et al. 2007), the Saos- 2 cells also did not cover the scaffold surface extensively. Therefore, the result obtained strongly indicates that the PLLA/CHAp nanocomposite microspheres offer a more biomimetic environment for attachment and proliferation of osteoblast-like cells. 

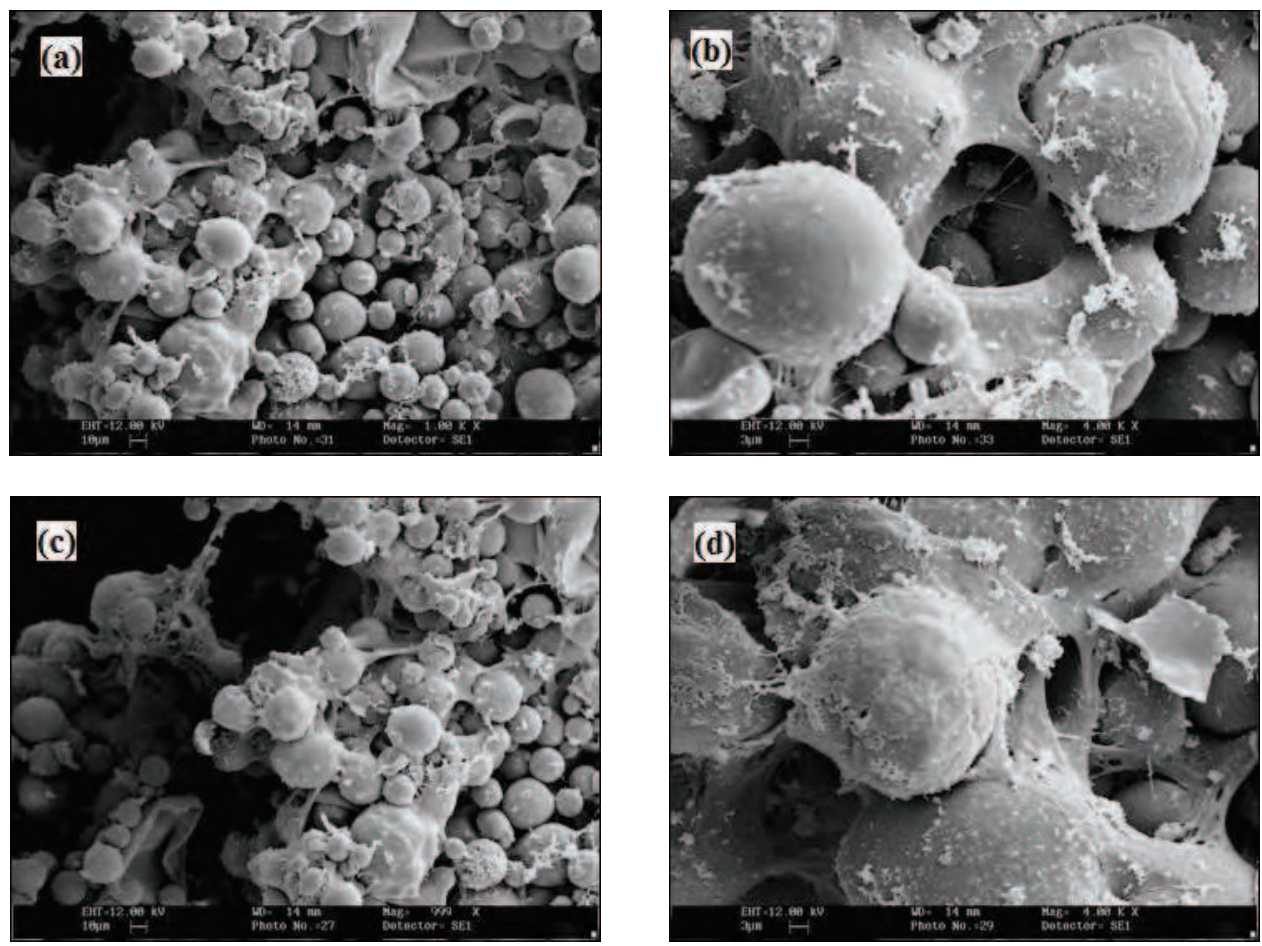

Fig. 18. SEM images of Type 1 PLLA scaffold seeded with Saos-2 cells: (a) 7 days after seeding and (b) close-up view of centre region in (a); (c) 14 days after seeding and (d) closeup view of centre region in (c), scaffold sintered at $15 \mathrm{~W}$.
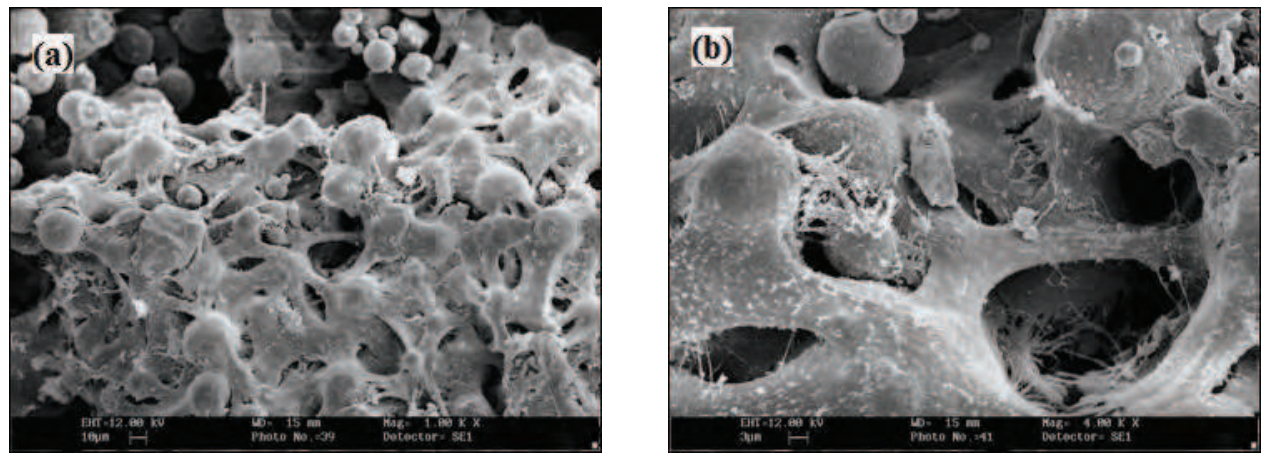

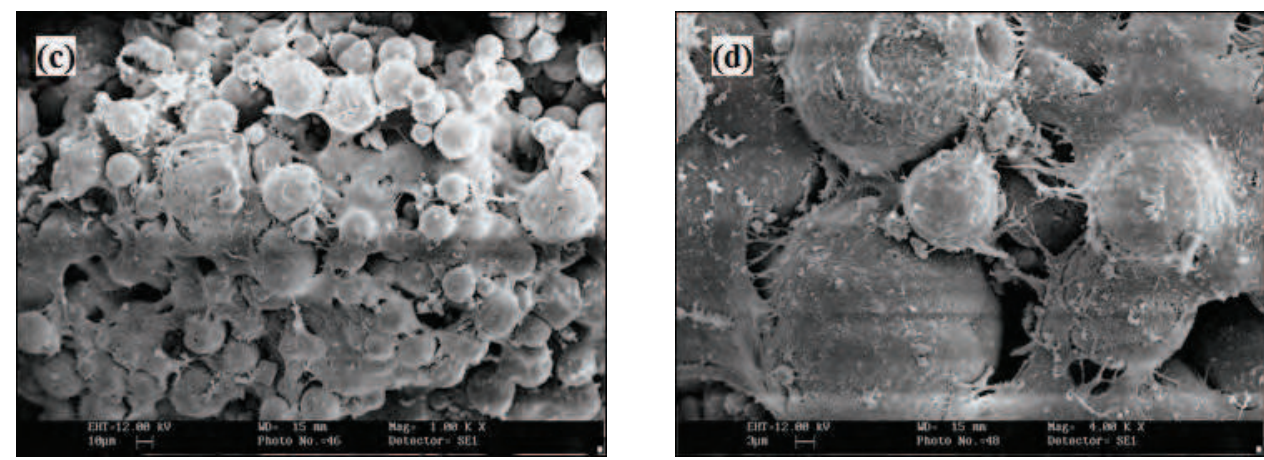

Fig. 19. SEM images of Type 1 PLLA/CHAp scaffold seeded with Saos-2 cells: (a) 7 days after seeding and (b) close-up view of centre region in (a); (c) 14 days after seeding and (d) close-up view of centre region in (c), scaffold sintered at $15 \mathrm{~W}$.

\section{Conclusions}

From this study, the following conclusions could be drawn:

(1) The custom-made miniature sintering platform allowed small quantities of the biomaterial powders to be processed in a commercial Sinterstation ${ }^{\circledR} 2000$ SLS machine. With this platform, prototypes of bone tissue engineering scaffolds with meso-scale feature were successfully built from PLLA microspheres and PLLA/CHAp nanocomposite microspheres.

(2) The effects of laser power, scan spacing and part bed temperature on the scaffold structure were studied and discussed. In general, extreme values of the processing parameters should be avoided in order to obtain desirable scaffold properties.

(3) The actual pore sizes obtained were smaller than the design values due to the phenomenon of "growth". Since "growth" cannot be avoided entirely, it should be accounted for in the design stage.

(4) The porosities of laser sintered PLLA and PLLA/CHAp scaffolds decreased almost linearly with increasing fill laser power within the recommended range. Furthermore, the sintered material was not fully dense. The degree of fusion of the PLLA/CHAp nanocomposite microspheres was lower than that of the pure PLLA powder. The phenomenon was caused by an increase in the molar heat capacity and viscosity of the nanocomposite powder after the addition of CHAp.

(5) The stress-strain curves of the scaffolds exhibited three regimes, i.e. linear elasticity, plateau and densification. The PLLA/CHAp scaffolds were found to have lower compressive yield strength and modulus than the PLLA scaffolds of the same type and sintering conditions. This could generally be attributed to the insufficient fusion of the PLLA/CHAp nanocomposite microspheres. Their compressive strength after optimization of the sintering condition would only match those of human cancellous bone.

(6) In the in vitro degradation test, most weight loss occurred in the first 2 weeks and it was mostly due to detachment of the microspheres loosely bonded on the scaffold surface and within the pores. This caused a corresponding drop in the compressive properties and the drop was more significant in modulus than in compressive yield strength for both the PLLA and PLLA/CHAp scaffolds. 
(7) Saos-2 cells were able to attach to both the PLLA and PLLA/CHAp scaffolds during the in vitro cell culture experiments. The PLLA/CHAp nanocomposite scaffolds showed a higher osteoconductivity than the neat PLLA scaffolds. The results strongly suggested that the PLLA/CHAp nanocomposite microspheres offered a more biomimetic environment than the pure PLLA microspheres for attachment and proliferation of osteoblast-like cells.

\section{Acknowledgements}

This work was fully supported by a General Research Fund (GRF) (HKU 7118/05E) from the Hong Kong Research Grants Council. The authors thank Mr. S.H. Lee (Department of Mechanical Engineering, HKU) for assisting the modification of Sinterstation ${ }^{\circledR} 2000$ SLS machine and Mr. C.K. Yuen (Department of Orthopaedics and Traumatology, HKU) for his help in the cell culture experiments. Dr. W.Y. Zhou sincerely thanks the University of Hong Kong for providing him the research studentship for the doctorate training.

\section{References}

ASTM (D695-02a). Standard test method for compressive properties of rigid plastics. PA, US, ASTM International: 1-8.

ASTM (D1621-04a). Standard test method for compressive properties of rigid cellular plastics. PA, US, ASTM International: 1-5.

Athanasiou, K. A., C. Zhu, et al. (2000). Fundamentals of biomechanics in tissue engineering of bone. Tissue Engineering 6, 4, 361-381.

Borden, M., S. F. El-Amin, et al. (2003). Structural and human cellular assessment of a novel microsphere-based tissue engineered scaffold for bone repair. Biomaterials 24, 4, 597-609.

Caulfield, B., P. E. McHugh, et al. (2007). Dependence of mechanical properties of polyamide components on build parameters in the SLS process. Journal of Materials Processing Technology 182, 1-3, 477-488.

Causa, F., P. A. Netti, et al. (2006). Poly-e-caprolactone/hydroxyapatite composites for bone regeneration: In vitro characterization and human osteoblast response. Journal of Biomedical Materials Research Part A 76A, 1, 151-162.

Childs, T. H. C. \& A. E. Tontowi (2001). Selective laser sintering of a crystalline and a glassfilled crystalline polymer: Experiments and simulations. Proceedings of the Institution of Mechanical Engineers Part B: Journal of Engineering Manufacture 215, 11, 1481-1495.

Chua, C. K., K. F. Leong, et al. (2004). Development of tissue scaffolds using selective laser sintering of polyvinyl alcohol/hydroxyapatite biocomposite for craniofacial and joint defects. Journal of Materials Science: Materials in Medicine 15, 10, 1113-1121.

Ciardelli, G., V. Chiono, et al. (2004). Innovative tissue engineering structures through advanced manufacturing technologies. Journal of Materials Science: Materials in Medicine 15, 4, 305-310.

Cruz, F., J. N. C. Lopes, et al. (2005). A Molecular dynamics study of the thermodynamic properties of calcium apatites. 1. hexagonal phases. Journal of Physical Chemistry. B, Condensed Matter, Materials, Surfaces, Interfaces, E Biophysical Chemistry 109, 51, 24473-24479. 
Das, S., S. J. Hollister, et al. (2003). Freeform fabrication of Nylon-6 tissue engineering scaffolds Rapid Prototyping Journal 9, 1, 43-49.

Dijk, M. v., D. C. Tunc, et al. (2002). In vitro and in vivo degradation of bioabsorbable PLLA spinal fusion cages. Journal of Biomedical Materials Research 63, 6, 752-759.

Fan, K. M. (2003). PhD Thesis: Heat Transfer Propertites and Fusion Behavior of Polymer Based Compoiste Powders in Selective Laser Sintering, The University of Hong Kong.

Fan, K. M., W. L. Cheung, et al. (2001). Material movement and fusion behavior of TrueForm and TrueForm/SiO2 during selective laser sintering. Proceedings of the 12th Annual Solid Freeform Fabrication Symposium, The University of Texas, Austin, TX146-154.

Froscha, K.-H., F. Barvencika, et al. (2002). Migration, Matrix Production and Lamellar Bone Formation of Human Osteoblast-Like Cells in Porous Titanium Implants. Cells Tissues Organs 170, 214-227.

Gibson, L. J. \& M. F. Ashby (1997). Cellular Solids: Structure and Properties. Cambridge, UK, Cambridge University Press.

Gong, Y., Q. Zhou, et al. (2007). In vitro and in vivo degradability and cytocompatibility of poly(l-lactic acid) scaffold fabricated by a gelatin particle leaching method. Acta Biomaterialia 3, 4, 531-540.

Guan, L. \& J. E. Davies (2004). Preparation and characterization of a highly macroporous biodegradable composite tissue engineering scaffold. Journal of Biomedical Materials Research Part A 71A, 3, 480-487.

Hao, L., M. M. Savalani, et al. (2006). Selective laser sintering of hydroxyapatite reinforced polyethylene composites for bioactive implants and tissue scaffold development. Proceedings of the Institution of Mechanical Engineers, Part H: Journal of Engineering in Medicine 220, 4, 521-531.

Harley, B. A., J. H. Leung, et al. (2007). Mechanical characterization of collagenglycosaminoglycan scaffolds. Acta Biomaterialia 3, 4, 463-474.

Hollister, S. J. (2005). Porous scaffold design for tissue engineering. Nature Materials 4, 7, 518524.

Kofron, M. D., J. A. Cooper Jr, et al. (2007). Novel tubular composite matrix for bone repair. Journal of Biomedical Materials Research Part A 82A, 2, 415-425.

Lee, G. \& J. W. Barlow (1993). Selective laser sintering of bioceramic materials for implants. Proceedings of the Solid Freeform Fabrication Symposium, Austin, TX376-380.

Lee, S. H. (2006). M.Phil. Thesis: Feasibility Study of Selective Laser Sintering of Biopolymer Scaffolds for Tissue Engineering, the University of Hong Kong.

Lee, S. H., W. Y. Zhou, et al. (2004). Selective laser sintering of porous scaffolds for bone tissue engineering. Proceedings of the Biomedical Engineering Conference (BME2004), Hong Kong.

Lu, H. H., S. F. El-Amin, et al. (2003). Three-dimensional, bioactive, biodegradable, polymerbioactive glass composite scaffolds with improved mechanical properties support collagen synthesis and mineralization of human osteoblast-like cellsin vitro. Journal of Biomedical Materials Research 64, 3, 465-474.

Mahoney, M. J., R. R. Chen, et al. (2005). The influence of microchannels on neurite growth and architecture. Biomaterials 26, 7, 771-778. 
Malmgren, T., J. Mays, et al. (2006). Characterization of poly(lactic acid) by size exclusion chromatography, differential refractometry, light scattering and thermal analysis. Journal of Thermal Analysis \& Calorimetry 83, 1, 35-40.

Navarro, M., S. del Valle, et al. (2004). New macroporous calcium phosphate glass ceramic for guided bone regeneration. Biomaterials 25, 18, 4233-4241.

Nelson, J. C., S. Xue, et al. (1993). Model of the selective laser sintering of bisphenol-a polycarbonate. Industrial \& Engineering Chemistry Research 32, 10, 2305-2317.

Park, T. G. (1995). Degradation of poly(lactic-co-glycolic acid) microspheres: effect of copolymer composition. Biomaterials 16, 15, 1123-1130.

Partee, B., S. J. Hollister, et al. (2006). Selective laser sintering process optimization for layered manufacturing of CAPA (R) 6501 polycaprolactone bone tissue engineering scaffolds. Journal of Manufacturing Science and Engineering 128, 2, 531-540.

Pyda, M., R. C. Bopp, et al. (2004). Heat capacity of poly(lactic acid). The Journal of Chemical Thermodynamics 36, 9, 731-742.

Rekow, D., P. Van Thompson, et al. (2006). Influence of scaffold meso-scale features on bone tissue response. Journal of Materials Science 41, 16, 5113-5121.

Rose, F. R., L. A. Cyster, et al. (2004). In vitro assessment of cell penetration into porous hydroxyapatite scaffolds with a central aligned channel. Biomaterials 25, 24, 5507-14.

Schieker, M., H. Seitz, et al. (2006). Biomaterials as scaffold for bone tissue engineering. European Journal of Trauma 32, 2, 114-124.

Shen, F. H., Q. Zeng, et al. (2006). Osteogenic differentiation of adipose-derived stromal cells treated with GDF-5 cultured on a novel three-dimensional sintered microsphere matrix. The Spine Journal 6, 6, 615-623.

Shieh, S.-J., S. Terada, et al. (2004). Tissue engineering auricular reconstruction: in vitro and in vivo studies. Biomaterials 25, 9, 1545-1557.

Sinha, A., G. Das, et al. (2007). Poly(vinyl alcohol)-hydroxyapatite biomimetic scaffold for tissue regeneration. Materials Science and Engineering: C 27, 1, 70-74.

Tan, K. H., C. K. Chua, et al. (2003). Scaffold development using selective laser sintering of polyetheretherketone-hydroxyapatite biocomposite blends. Biomaterials 24, 18, 3115-23.

Venuvinod, P. K. \& W. Ma (2004). Selective Laser Sintering (SLS). Rapid prototyping : laserbased and other technologies. Boston Kluwer Academic: 248.

von Burkersroda, F., L. Schedl, et al. (2002). Why degradable polymers undergo surface erosion or bulk erosion. Biomaterials 23, 21, 4221-4231.

Williams, J. M., A. Adewunmi, et al. (2005). Bone tissue engineering using polycaprolactone scaffolds fabricated via selective laser sintering. Biomaterials 26, 23, 4817-4827.

Wiria, F. E., K. F. Leong, et al. (2007). Poly- $\varepsilon$-caprolactone/hydroxyapatite for tissue engineering scaffold fabrication via selective laser sintering. Acta Biomaterialia 3, 1, 1-12.

$\mathrm{Xu}$, S., D. Li, et al. (2007). Fabrication of a calcium phosphate scaffold with a three dimensional channel network and its application to perfusion culture of stem cells. Rapid Prototyping Journal 13, 2, 99-106.

Yang, F., W. Cui, et al. (2006). Poly(l,l-lactide-co-glycolide)/tricalcium phosphate composite scaffold and its various changes during degradation in vitro. Polymer Degradation and Stability 91, 12, 3065-3073. 
Yang, S., K. F. Leong, et al. (2002). The design of scaffolds for use in tissue engineering. part II. rapid prototyping techniques. Tissue Engineering 8, 1, 1-11.

Zhou, W. Y., S. H. Lee, et al. (2007). Selective laser sintering of tissue engineering scaffolds using poly(L-Lactide) microspheres. Key Engineering Materials 334-335, 1225-1228.

Zhou, W. Y., S. H. Lee, et al. (2008). Selective laser sintering of porous tissue engineering scaffolds from poly(L-lactide)/carbonated hydroxyapatite nanocomposite microspheres. Journal of Materials Science: Materials in Medicine 19, 7, 2535-2540.

Zhou, W. Y., M. Wang, et al. (2007). Fabrication and characterization of composite microspheres containing carbonated hydroxyapatite nanoparticles. Key Engineering Materials 334-335, 1221-1224.

Zhou, W. Y., M. Wang, et al. (2008). Synthesis of carbonted hydroxyapatite nanospheres through nanoemulsion. Journal of Materials Science: Materials in Medicine 19, 1, 103110 . 


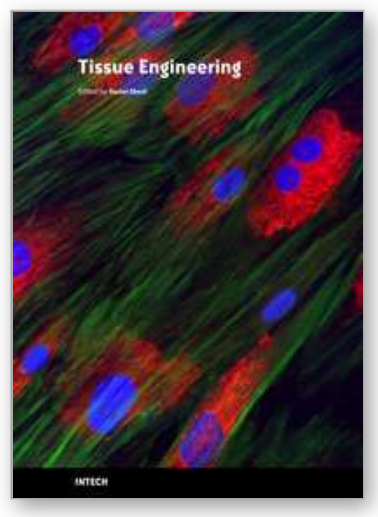

\author{
Tissue Engineering \\ Edited by Daniel Eberli
}

ISBN 978-953-307-079-7

Hard cover, 524 pages

Publisher InTech

Published online 01, March, 2010

Published in print edition March, 2010

The Tissue Engineering approach has major advantages over traditional organ transplantation and circumvents the problem of organ shortage. Tissues that closely match the patient's needs can be reconstructed from readily available biopsies and subsequently be implanted with minimal or no immunogenicity. This eventually conquers several limitations encountered in tissue transplantation approaches. This book serves as a good starting point for anyone interested in the application of Tissue Engineering. It offers a colorful mix of topics, which explain the obstacles and possible solutions for TE applications.

\title{
How to reference
}

In order to correctly reference this scholarly work, feel free to copy and paste the following:

Wen You Zhou, Min Wang, Wai Lam Cheung and Wing Yuk Ip (2010). Selective Laser Sintering of Poly(LLactide)/Carbonated Hydroxyapatite Nanocomposite Porous Scaffolds for Bone Tissue Engineering, Tissue Engineering, Daniel Eberli (Ed.), ISBN: 978-953-307-079-7, InTech, Available from:

http://www.intechopen.com/books/tissue-engineering/selective-laser-sintering-of-poly-l-lactide-carbonatedhydroxyapatite-nanocomposite-porous-scaffolds

\section{INTECH}

open science | open minds

\section{InTech Europe}

University Campus STeP Ri

Slavka Krautzeka 83/A

51000 Rijeka, Croatia

Phone: +385 (51) 770447

Fax: +385 (51) 686166

www.intechopen.com

\section{InTech China}

Unit 405, Office Block, Hotel Equatorial Shanghai

No.65, Yan An Road (West), Shanghai, 200040, China

中国上海市延安西路65号上海国际贵都大饭店办公楼405单元

Phone: +86-21-62489820

Fax: +86-21-62489821 
(C) 2010 The Author(s). Licensee IntechOpen. This chapter is distributed under the terms of the Creative Commons Attribution-NonCommercialShareAlike-3.0 License, which permits use, distribution and reproduction for non-commercial purposes, provided the original is properly cited and derivative works building on this content are distributed under the same license. 